\title{
Ionization and hydrolysis of dinitrogen pentoxide in low-temperature solids
}

\author{
J. Agreiter, M. Frankowski*, and V. E. Bondybey \\ Institute for Physical and Theoretical Chemistry, Technical University of Munich \\ Lichtenbergstrasse 4, 85747 Garching, Germany \\ E-mail: bondybey@uci.edu \\ Received June 21, 2001
}

\begin{abstract}
Solid layers of interest for the chemistry of polar stratospheric clouds were investigated. Mixtures of covalent $\mathrm{N}_{2} \mathrm{O}_{5}$ and water in various molar ratios are deposited from vapor phase on a cold $12 \mathrm{~K}$ substrate. By repeatedly recording Fourier transform infrared spectra of the samples during gradual warm up to $200 \mathrm{~K}$ over a period of several hours the hydrolysis process can be followed. At each concentration the process is found to proceed in several distinct steps with sharp temperature thresholds. In samples containing only small amounts of water the covalent $\mathrm{N}_{2} \mathrm{O}_{5}$ is first around $110 \mathrm{~K}$ converted to an ionic nitronium nitrate, and only in a subsequent step $\mathrm{NO}_{2}^{+} \mathrm{NO}_{3}^{-}$reacts to nitric acid.
\end{abstract}

PACS: 78.30.-j

\section{Introduction}

Structures, optical spectra, and other properties of molecules in condensed phases often differ quite substantially from those in the gas phase. Strongly polar compounds like $\mathrm{HCl}$ or $\mathrm{HI}$, which occur as covalent compounds in the gas phase, ionize spontaneously when dissolved in water. Even though the autoionizing reaction of water itself, $2 \mathrm{H}_{2} \mathrm{O} \rightarrow \mathrm{H}_{3} \mathrm{O}^{+}+$ $+\mathrm{OH}^{-}$requires an energy $H=933 \mathrm{~kJ} / \mathrm{mol}$, every litre of pure room temperature water contains in thermal equilibrium some $10^{17} \mathrm{H}_{3} \mathrm{O}^{+}$cations, and a corresponding number of $\mathrm{OH}^{-}$anions, which greatly affect its properties. Some substances, which are in the gas phase present in a covalent form, tend to completely ionize in solid or liquid where the substance itself acts as its own «solvent». While in the gas phase a covalent form $A B$ is usually lower in energy, in a condensed phase where an $\mathrm{A}^{+}$ion can interact with a number of nearby $\mathrm{B}^{-}$ anions, the lattice energy may more than compensate for this deficit, and the ionic $\mathrm{A}^{+} \mathrm{B}^{-}$alternative becomes energetically preferable. A well known example of this type is dinitrogen pentoxide, $\mathrm{N}_{2} \mathrm{O}_{5}$, which occurs in the gas phase in the form of covalent $\mathrm{O}_{2} \mathrm{~N}-\mathrm{O}-\mathrm{NO}_{2}$ molecules, but in the solid usually like an ionic $\mathrm{NO}_{2}^{+} \mathrm{NO}_{3}^{-}$, nitronium nitrate $[1,2]$.

\section{Nitrogen oxide in the stratosphere}

Nitrogen oxides and their condensation are of considerable importance in the chemistry of stratosphere, and contribute in several ways to the balance of stratospheric ozone [3-8]. The major path of $\mathrm{N}_{2} \mathrm{O}_{5}$ formation is due to reaction of nitric oxide with ozone $[9,10]$ :

$$
\begin{gathered}
\mathrm{NO}_{2}+\mathrm{O}_{3} \rightarrow \mathrm{NO}_{3}+\mathrm{O}_{2}, \\
\mathrm{NO}_{2}+\mathrm{NO}_{3}(+M) \rightarrow \mathrm{N}_{2} \mathrm{O}_{5}(+M) .
\end{gathered}
$$

Since during the daytime $\mathrm{NO}_{3}$ is efficiently photolyzed by sunlight, the $\mathrm{N}_{2} \mathrm{O}_{5}$ concentration reaches its maximum at night. The dinitrogen pentoxide is ultimately also photolyzed back to $\mathrm{NO}_{2}+\mathrm{NO}_{3}$, but it acts as a relatively unreactive «reservoir» reducing, albeit temporarily, the concentration of the so-called $\mathrm{NO}_{x}$ or «odd nitrogen» species. These, and in particular $\mathrm{NO}_{2}$, in turn have importance in reacting with $\mathrm{ClO}$ to form the relatively unreactive chlorine nitrate, $\mathrm{ClONO}_{2}$, thus removing reactive chlorine from a catalytic, ozone destroying cycle.

Perhaps somewhat paradoxically for the rarefied stratosphere, properties of $\mathrm{N}_{2} \mathrm{O}_{5}$ and other nitrogen oxide in solid phase or on solid surfaces may be even more important for stratospheric chemistry than

* Permanent address: Institute of Fluid-Flow Machinery, Polish Academy of Sciences, J. Fiszera 14, 80-231 Gdańsk, Poland 
their gas phase reactions [3-8]. When in the course of the polar winter the temperature of the stratosphere drops below about $190 \mathrm{~K}$, a formation of the so-called polar stratospheric clouds (PSCs) takes place. These consist of micron-size particles, whose main components are water and the oxides of nitrogen. Heterogeneous processes on their surfaces are then believed to be responsible for converting relatively unreactive, so-called «reservoir» chlorine containing compounds, mainly chlorine nitrate and hydrogen chloride, into more active species, such as $\mathrm{Cl}_{2}$ or NOCl. During polar spring when the temperature rises again, and the PSCs evaporate, chlorine in this more reactive form is returned into the gas phase, with their photolysis yielding atomic chlorine. $\mathrm{Cl}$ atoms then very efficiently catalyze the $\mathrm{O}_{3}$ destruction, and are ultimately responsible for the seasonal ozone depletion and catalytic destruction, referred to popularly as «ozone hole».

Also the relatively nonvolatile dinitrogen pentoxide condenses on the surface of PSCs, and contributes in a variety of ways to the ozone and its balance. Important is the hydrolysis of $\mathrm{N}_{2} \mathrm{O}_{5}$ to form nitric acid, presumably by the reaction catalyzed on a PSC surface [11-13]:

$$
\mathrm{N}_{2} \mathrm{O}_{5}+\mathrm{H}_{2} \mathrm{O} \rightarrow 2 \mathrm{HNO}_{3} .
$$

This reaction is in fact believed to be the major pathway of «denitrification» of the stratosphere, that is for the loss of $\mathrm{NO}_{x}$ species, and thus to contribute indirectly to an increase in the concentrations of active chlorine radicals and to ozone destruction. The nitric acid concentration also affects the PSC formation itself: the so-called type II PSCs, containing nitric oxides and in particular nitric acid trihydrate (NAT), can form at a higher temperature than «pure water», type I PSCs. While the above hydrolytic reaction forming nitric acid could in principle also occur during gas phase collisions, this is believed to be far too inefficient to explain the observed chemistry.

This added practical importance of $\mathrm{N}_{2} \mathrm{O}_{5}$ and of its condensation and hydrolysis has motivated a number of recent experimental and theoretical studies. Thin layers consisting of nitrogen oxides, nitric acid and water were studied by spectroscopy, and also their reactions were extensively investigated at a variety of temperatures. Also theoretical, ab initio or density functional theory (DFT) studies of $\mathrm{N}_{2} \mathrm{O}_{5}$ and its hydrolysis have appeared [14]. In spite of this extensive attention, numerous open or controversial problems remain. A considerable discussion centered on the question of whether the reactants occur and the reaction products are formed in an ionized or in a molecular form. Based on infrared study it was concluded that $\mathrm{N}_{2} \mathrm{O}_{5}$ itself does not play directly a major role in the heterogeneous chemistry, but rather through its hydrolysis products. The structure and reactivity of nitrogen oxides is known to be a sensitive function of their temperature and of the dynamics of their formation. To gain additional insights, we reinvestigate here the $\mathrm{N}_{2} \mathrm{O}_{5}$ hydrolysis using Fourier transform infrared (FTIR) spectroscopy.

Even though in solid the ionic $\mathrm{NO}_{2}^{+} \mathrm{NO}_{3}^{-}$form is lower in energy, if a gaseous dinitrogen pentoxide is condensed on a very cold surface, a solid consisting of discrete, covalent $\mathrm{N}_{2} \mathrm{O}_{5}$ molecules is formed, whose infrared or Raman spectra are very similar to the gas phase spectrum. When the energy needed to overcome the activation barrier is supplied, either by optical irradiation, or by heating the sample, it is converted into the ionic form. As is well known, annealing such samples above about $120 \mathrm{~K}$, results in an abrupt and complete change in the structure of the solid, and naturally also in its infrared or Raman spectrum. In the present work we take advantage of the ability of a modern FTIR instrument to rapidly acquire and store digitally infrared spectra. We prepare by deposition from the gas phase solid mixtures of water and covalent $\mathrm{N}_{2} \mathrm{O}_{5}$ at about $12 \mathrm{~K}$. Then we slowly allow the samples to warm up over several hours, and take repetitively infrared spectra every few minutes. The spectra then provide information about structural changes, phase transitions or chemical reactions taking place in the solid. The interpretation of the results is naturally greatly assisted by the availability of numerous previous studies of the spectroscopy of nitrogen oxides, nitric acid, and of its hydrates.

\section{Experimental}

The $\mathrm{N}_{2} \mathrm{O}_{5}$ prepared in a standard way by the reaction of commercial nitric oxide $\left(\right.$ or $\mathrm{N}_{2} \mathrm{O}_{4}$ ) with ozone was purified by vacuum distillation and by several pump-freeze-thaw cycles. The oxide stored in pyrex containers at liquid nitrogen temperature was then deposited via a corrosion resistant needle valve onto a metal substrate cooled to $\sim 12 \mathrm{~K}$ by a closed cycle refrigerator. Simultaneously with $\mathrm{N}_{2} \mathrm{O}_{5}$ water was deposited from a separate inlet, to yield a solid mixture in a desired molar ratio of $\mathrm{H}_{2} \mathrm{O}: \mathrm{N}_{2} \mathrm{O}_{5}$. Infrared spectra were recorded on a Bruker IFS 120 HR Fourier transform spectrometer. The 100-300 spectra acquired during over 4-6 h during the slow sample warm-up could then be used and displayed in a variety of ways. Initial spectra, final spectra, or intermediate spectra at any time 
during the warm-up could be plotted. Alternatively, by plotting the absorption at a selected wavelength, the decay of a reacting compound or the appearance a products as a function of time and temperature could be displayed. Finally one could produce a «three-dimensional» diagram with the abscissa indicating the wavenumber, the ordinate the time - or the temperature which was rising approximately linearly with time, and in «color» or shade of gray the band intensity. In the samples studied here there was little change in the spectrum up to about $100 \mathrm{~K}$. To shorten the duration of the experiments, the sample temperature was first «rapidly», over about ten minutes, raised to $80 \mathrm{~K}$. After that it was over the course of about 4-6 h allowed to rise further to about $160-200 \mathrm{~K}$, at which point the experiment was terminated and the sample allowed to evaporate.

\section{Results and discussion}

Figure 1 exemplifies the results of such an experiment obtained with a sample containing $\mathrm{N}_{2} \mathrm{O}_{5}$ with a relatively low water concentration $\left(\mathrm{H}_{2} \mathrm{O}: \mathrm{N}_{2} \mathrm{O}_{5}\right.$ molar ratio $\left.0.25: 1\right)$ deposited at a temperature of $\sim 12 \mathrm{~K}$. The initial spectrum in the bottom trace of Fig. 1 shows the known bands of the covalent $\mathrm{N}_{2} \mathrm{O}_{5}$, e.g., near 1740,1240 and $756 \mathrm{~cm}^{-1}$, most of which are only slightly shifted with respect to the gas phase. The presence of water is evidenced by the broad band centered near $3350 \mathrm{~cm}^{-1}$.

As the sample is warmed up, the spectrum initially remains unchanged until about $110 \mathrm{~K}$ is reached. Here over a temperature range of less than $10 \mathrm{~K}$ the covalent $\mathrm{N}_{2} \mathrm{O}_{5}$ bands nearly completely disappear, and are replaced by absorptions of the ionic solid, the most characteristic being the asymmetric stretch of the $\mathrm{NO}_{2}^{+}$, nitronium cation at $2386 \mathrm{~cm}^{-1}$, and the $v_{2}$ vibration of the nitrate anion near $820 \mathrm{~cm}^{-1}$. A simple program was written which displays the information obtained from the repetitive spectral scans during the sample warm-up in the form of a colored two dimensional diagram, in which the spectral changes occurring in the sample can be very nicely seen. As an example we present in Fig. 2 a black and white version of one of these diagrams. Even though in the shades of gray version the changes are much less apparent, one can still follow the disappearance of the covalent solid and growth of the ionic solid as a function of time.

With some time delay after the conversion to ionic $\mathrm{N}_{2} \mathrm{O}_{5}$ is complete, a second, less prominent change occurs in the spectrum near $140 \mathrm{~K}$, when bands of nitric acid begin to grow in. While some of

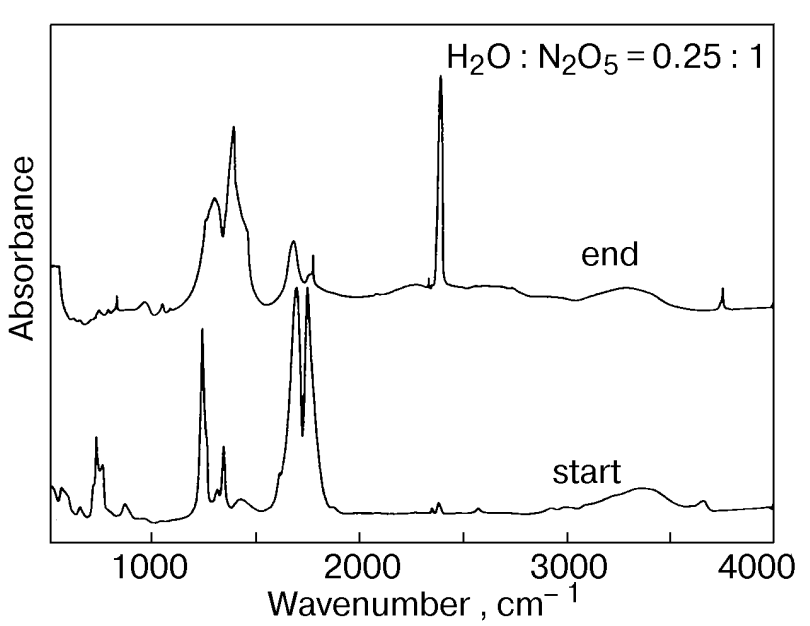

Fig. 1. Experiment with $\mathrm{H}_{2} \mathrm{O}: \mathrm{N}_{2} \mathrm{O}_{5}$ ratio of about 0.25:1. The initial $10 \mathrm{~K}$ infrared spectrum of covalent $\mathrm{N}_{2} \mathrm{O}_{5}$ in the bottom trace is in the top trace after gradual annealing over $4 \mathrm{~h}$ to $160 \mathrm{~K}$ converted to ionic $\mathrm{N}_{2} \mathrm{O}^{+} \mathrm{NO}_{3}^{-}$, with small amounts of nitric acid, $\mathrm{HNO}_{3}$.

these are partially overlapped, the $\mathrm{HNO}_{3}$ absorptions are easily identified near 775 and $945 \mathrm{~cm}^{-1}$. Another strong $\mathrm{HNO}_{3}$ band, nearly coincident with an $\mathrm{N}_{2} \mathrm{O}_{5}$ absorption occurs around $1680 \mathrm{~cm}^{-1}$. The final spectrum resulting from annealing of the sample to $160 \mathrm{~K}$ can be seen in the top trace of Fig. 1, where the nitric acid bands can be easily identified. These observations provide clear evidence that under the conditions of our experiments, the neutral dinitrogen pentoxide does not react with the water Low water concentration

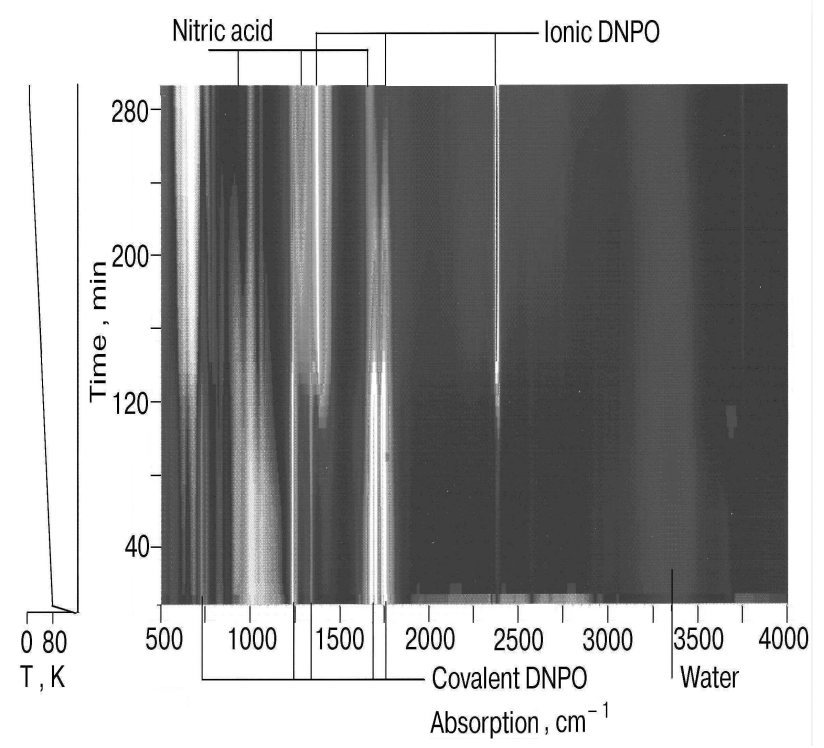

Fig. 2. $\ll 3 \mathrm{D} \gg$ diagram, from the same experiment showing the changes of spectrum during the controlled warm-up. The initial bands of covalent $\mathrm{N}_{2} \mathrm{O}_{5}$ disappear after $\sim 120 \mathrm{~min}$ (at $110 \mathrm{~K}$ ), with concurrent appearance of the ionic nitronium nitrate. After about $220 \mathrm{~min}(\sim 140 \mathrm{~K})$ nitric acid bands appear. 


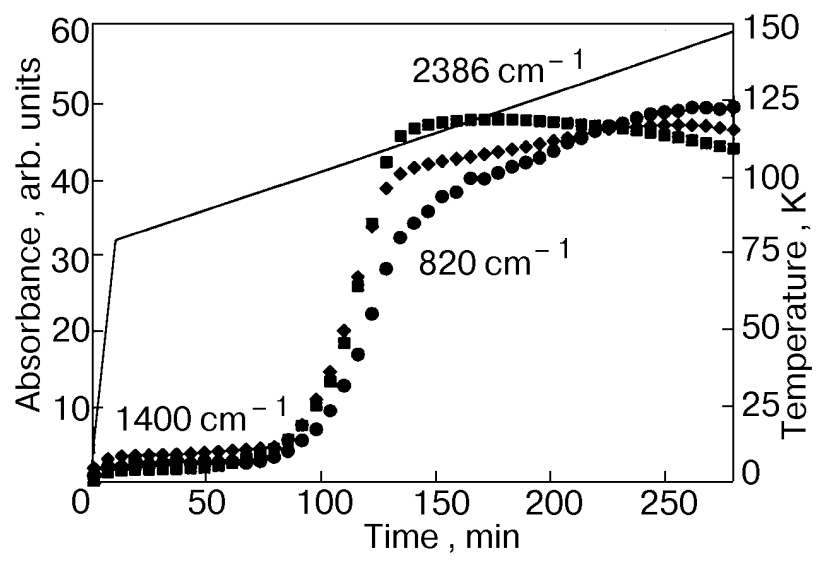

Fig. 3. Intensity profiles showing the simultaneous growth of the $\mathrm{N}_{2} \mathrm{O}^{+} \mathrm{NO}_{3}^{-}$bands within a relatively narrow, $\sim 5 \mathrm{~K}$ temperature range.

present in the sample. The formation of nitric acid only takes place with a considerable delay, after a complete conversion of the nitrogen pentoxide solid into an ionic form.

A different presentation of these data and of the conversion of the covalent dinitrogen pentoxide into the ionic nitronium nitrate is shown in Fig. 3. Here one can see the simultaneous and abrupt appearance of the ionic solid absorptions at 820 , 1400 and $2386 \mathrm{~cm}^{-1}$ after about $115 \mathrm{~min}$ during controlled sample heating. The spectral change occurs within a narrow range around $110 \mathrm{~K}$, and concurrently one can observe a decrease in the absorptions due to the covalent pentoxide. Note that the thin solid line gives the changes in the sample temperature, as indicated by the right hand scale.

The formation of nitric acid hydrates which are particularly important in the formation and chemistry of polar stratospheric clouds, and apparently in the ozone balance, can be studied by increasing the proportion of water in the deposited $\mathrm{H}_{2} \mathrm{O}: \mathrm{N}_{2} \mathrm{O}_{5}$ samples [15-18]. Interesting are the intermediate concentration samples with an $\mathrm{H}_{2} \mathrm{O}: \mathrm{N}_{2} \mathrm{O}_{5}$ ratio of about $3: 1$, stoichiometry which should lead to nitric acid monohydrate (NAM):

$$
\mathrm{N}_{2} \mathrm{O}_{5}+3 \mathrm{H}_{2} \mathrm{O} \rightarrow 2 \mathrm{HNO}_{3} \cdot \mathrm{H}_{2} \mathrm{O} \rightarrow 2 \mathrm{H}_{3} \mathrm{O}^{+} \mathrm{NO}_{3}^{-} \text {. }
$$

Such a sample when deposited at $12 \mathrm{~K}$ shows again a superposition of the spectrum of covalent $\mathrm{N}_{2} \mathrm{O}_{5}$ with in this case a much more prominent water band near $3360 \mathrm{~cm}^{-1}$, as shown in the Fig. 4 . Interestingly, a minor amount of the ionic form seems to be present, perhaps small «clusters» whose conversion during deposition is «catalyzed» by the

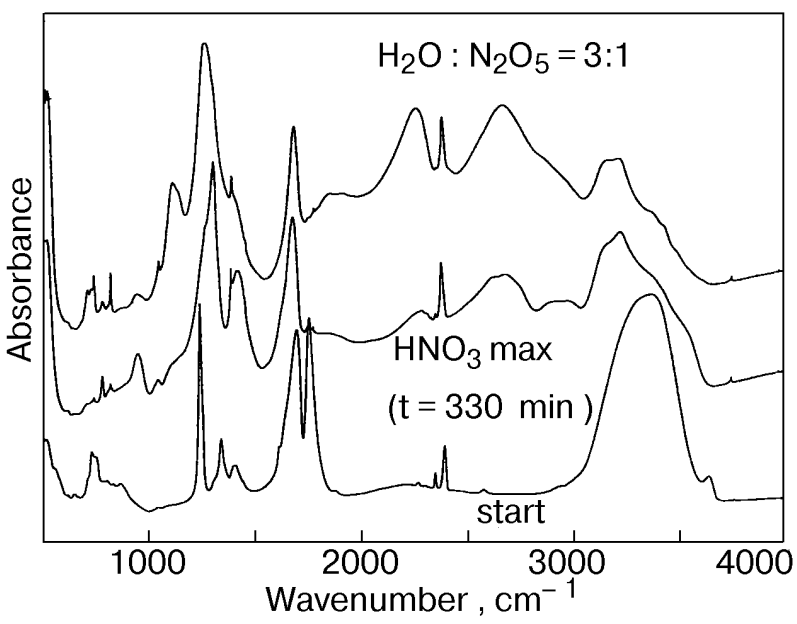

Fig. 4. Experiment with $\mathrm{H}_{2} \mathrm{O}: \mathrm{N}_{2} \mathrm{O}_{5}$ ratio of $3: 1$, corresponding to nitric acid monohydrate (NAM). The initial, bottom spectrum shows mainly covalent $\mathrm{N}_{2} \mathrm{O}_{5}$, and a very strong, broad water band near $3360 \mathrm{~cm}^{-1}$. The middle spectrum after 330 min exhibits maximum $\mathrm{HNO}_{3}$ concentration. The top spectrum after $400 \mathrm{~min}$ is mainly that of the NAM.

water rich surface. During the warm-up little happens until about $130 \mathrm{~K}$ is reached, when major changes in the spectrum begin to take place. In the first step the bands of the covalent $\mathrm{N}_{2} \mathrm{O}_{5}$ start to disappear, with simultaneous appearance of the absorptions of nitric acid. The concentration of $\mathrm{HNO}_{3}$ which can be followed by monitoring its absorptions near 775 and $945 \mathrm{~cm}^{-1}$ reaches a maximum near $145 \mathrm{~K}$ when it starts to disappear again. Before the final temperature of $180 \mathrm{~K}$ is reached, the nitric acid is completely replaced by NAM. This is best identified by the $\mathrm{H}_{3} \mathrm{O}^{+}$absorptions near 1670,2250 and $2650 \mathrm{~cm}^{-1}$, and nitrate anion bands near 735, 812 and $1260 \mathrm{~cm}^{-1}$. The absorptions of NAM then remain until the sample is lost.

A considerably different behavior can be found in samples containing still larger relative concentrations of water, where one can naturally observe a higher degree of nitric acid hydration. As in the less concentrated samples, the reaction again proceeds in several distinct steps. Such an experiment is presented in Fig. 5, where the molar ratio of $\mathrm{H}_{2} \mathrm{O}$ to $\mathrm{N}_{2} \mathrm{O}_{5}$ was about $8: 1$, allowing formation of nitric acid trihydrate:

$$
\mathrm{N}_{2} \mathrm{O}_{5}+7 \mathrm{H}_{2} \mathrm{O} \rightarrow 2 \mathrm{HNO}_{3} \cdot 3 \mathrm{H}_{2} \mathrm{O} \rightarrow 2 \mathrm{H}_{7} \mathrm{O}_{3}^{+} \mathrm{NO}_{3}^{-} \text {. }
$$

In this case conversion of $\mathrm{N}_{2} \mathrm{O}_{5}$ from covalent to ionic form is hardly observed at all, with the covalent form persisting up to about $150 \mathrm{~K}$. Apparently under these conditions one effectively has discrete $\mathrm{N}_{2} \mathrm{O}_{5}$ monomers «isolated» in water glass. 


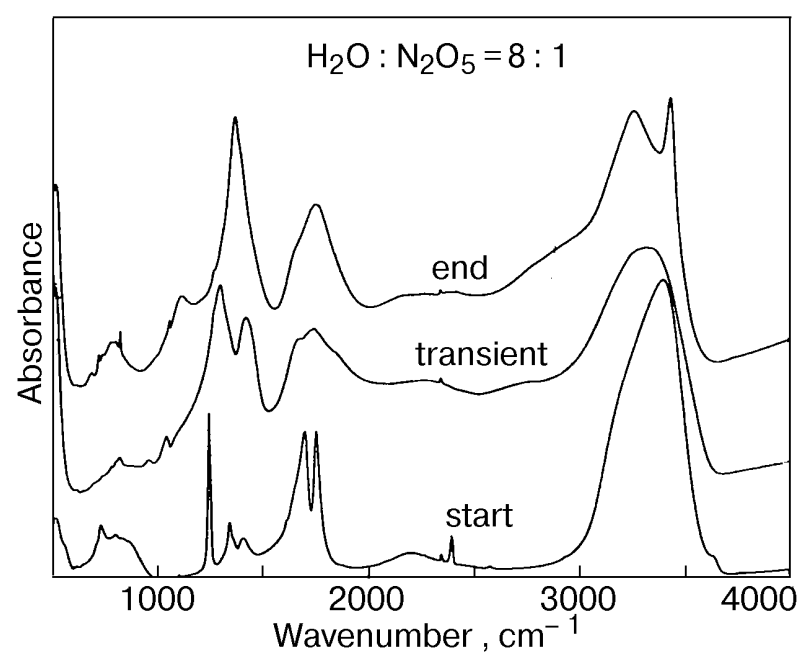

Fig. 5. $\mathrm{H}_{2} \mathrm{O}: \mathrm{N}_{2} \mathrm{O}_{5}$ ratio of about 8 , with enough water to form nitric acid trihydrate, NAT. The initial, bottom spectrum contains covalent $\mathrm{N}_{2} \mathrm{O}_{5}$, and a strong water band. In the middle spectrum after about $300 \mathrm{~min}(\sim 140 \mathrm{~K})$ the dinitrogen pentoxide has disappeared, and the observed absorptions agree with the known spectrum of NAD. After $320 \mathrm{~min}(\sim 145 \mathrm{~K})$ another sharp change takes place and the top spectrum identified as NAT results as final product.

As the temperature is gradually raised, the changes start only above $140 \mathrm{~K}$, but unlike in the more concentrated $\mathrm{N}_{2} \mathrm{O}_{5}$ case, neither nitric acid, nor nitric acid monohydrate is detected. The new bands, which grow in, can on the basis of previous spectroscopic work [15-19] be easily identified as nitric acid dihydrate (NAD). The most characteristic feature are two strong bands near 1290 and $1420 \mathrm{~cm}^{-1}$, interpreted previously in terms of the asymmetric nitrate stretching mode split by the asymmetric environment. The NAD bands do, however, not persist long, but are at $155 \mathrm{~K}$ abruptly replaced by the spectrum of the final product, the nitric acid trihydrate. In NAT the two nitrate stretching bands collapse to a single strong absorption at $1390 \mathrm{~cm}^{-1}$, and two bands appear in the $\mathrm{OH}$ stretching region, a sharper one at $3424 \mathrm{~cm}^{-1}$, and a much broader band near $3205 \mathrm{~cm}^{-1}$. The apparently quite stable trihydrate, NAT, which is believed to be one of the major components of the polar stratospheric clouds then remains unchanged until the sample is lost.

Similar to Fig. 3, Fig. 6 shows the time dependent change in the product infrared absorption intensities for the 8:1 sample of Fig. 5, as demonstrated by the $1030 \mathrm{~cm}^{-1}$ band, at a temperature near $145 \mathrm{~K}$ the NAD appears but only transiently, only to be replaced by the strong $1100 \mathrm{~cm}^{-1}$ band of the final product, NAT.

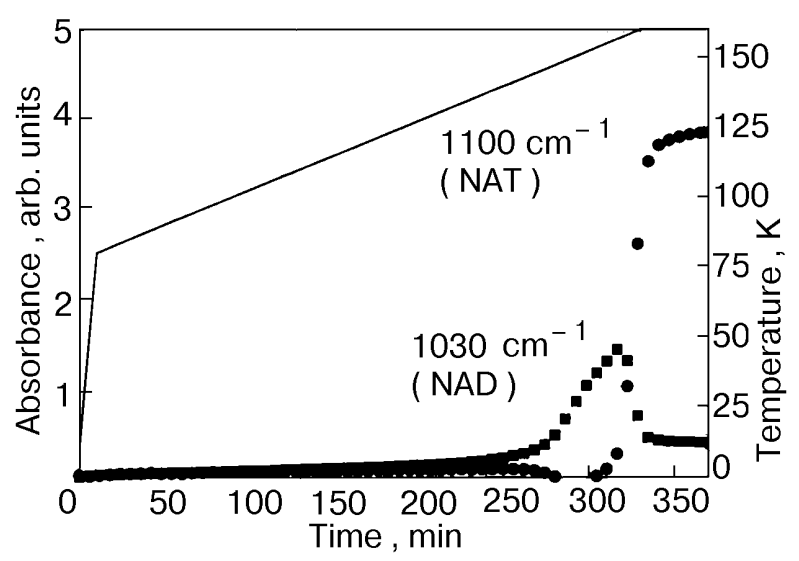

Fig. 6. Time resolved intensity profiles showing the NAD absorptions growing in after $\sim 280 \mathrm{~min}$, reaching a maximum after $\sim 305 \mathrm{~min}(\sim 145 \mathrm{~K})$ and then abruptly disappear with concurrent appearance of the NAT.

\section{Summary}

In summary, in this manuscript we investigate the structural changes in solid layers with relevance to the chemistry of PSCs. We condense the samples at low temperatures, and record then repeatedly their infrared spectra as a function of time as the sample temperature is slowly raised, to gain insight into processes and structural changes which take place. We find that the hydrolysis of $\mathrm{N}_{2} \mathrm{O}_{5}$ proceeds in each case in several well defined sequential steps. Specifically in samples of dinitrogen pentoxide, there is a distinct transition to an ionic $\mathrm{NO}_{2}^{+} \mathrm{NO}_{3}^{-}$ form around $120 \mathrm{~K}$. When only small amounts of water $(\sim 0.2: 1)$ are present, a further reaction to form nitric acid occurs only with delay, after a complete conversion into the ionic form. When enough water is present $(>3: 1)$, the nitric acid produced in the first step reacts after some delay further with water to NAM. In samples containing a large excess of water $(>7: 1)$, almost no conversion of the pentoxide into an ionic form takes place. The covalent form persists up to about $150 \mathrm{~K}$, where it directly reacts with $\mathrm{H}_{2} \mathrm{O}$ first to yield nitric acid dihydrate, and in a second reaction step finally to trihydrate.

1. R. Teranishi and J. C. Decius, J. Chem. Phys. 22, 896 (1954).

2. E. Grison, K. Eriks, and J. L. de Vries, Acta Cryst. 3, 290 (1950).

3. S. Solomon, R. R. Garcia, F. S. Rowland, and D. J. Wuebbles, Nature 321, 755 (1986).

4. M. Molina, T. L. Tsao, L. T. Molina, and F. C. Y. Wang, Science 238, 1253 (1987).

5. S. Solomon, Nature 347, 347 (1990).

6. M. A. Tolbert, Science 264, 527 (1994). 
7. A. G. Russell, G. J. McRae, and G. R. Cass, Atmos. Environ. 19, 893 (1985).

8. T. F. Mentel, D. Bleilebens, and A. Wahner, Atmos. Environ. 30, 4007 (1996).

9. C. R. Webster, R. D. May, R. Toumi, and R. Pyle, J. Geophys. Res. 95, 13851 (1990).

10. F. J. Dentener and P. J. Crutzen, J. Geophys. Res. 98, 7949 (1993).

11. M. T. Leu, Geophys. Res. Lett. 15, 851 (1988).

12. D. R. Hanson and A. R. Ravishankara, J. Geophys. Res. 96, 5081 (1991).

13. M. A. Quinlan, C. M. Reihs, D. M. Golden, and M. A. Tolbert, J. Phys. Chem. 94, 3255 (1990).
14. J. P. McNamara and I. H. Hillier, J. Phys. Chem. A104, $5307(2000)$.

15. G. Ritzhaupt and J. P. Devlin, J. Phys. Chem. 95, 90 (1991).

16. B. G. Koehler, A. M. Middlebrook, and M. A. Tolbert, J. Geophys. Res. 97, 8065 (1992).

17. N. Barton, B. Rowland, and J. P. Devlin, J. Phys. Chem. 97, 5848 (1993).

18. R. H. Smith, M. T. Leu, and L. F. Keyser, J. Phys. Chem. 95, 5924 (1991).

19. A. B. Horn, T. Koch, M. A. Chesters, M. R. S. McCoustra, and J. R. Sodeau, J. Phys. Chem. 98, 946 (1994). 